Cite this: Nanoscale, 2014, 6, 1153

\title{
A DFT study of oxygen dissociation on platinum based nanoparticles $\uparrow$
}

\author{
Paul C. Jennings, ${ }^{a}$ Hristiyan A. Aleksandrov, ${ }^{\text {bc }}$ Konstantin M. Neyman ${ }^{\text {bd }}$ \\ and Roy L. Johnston*e
}

Density functional theory calculations are performed on 38 and 79 metal atom truncated octahedron clusters to study oxygen dissociation as a model for the initial stage of the oxygen reduction reaction. Pure platinum and alloyed platinum-titanium core-shell systems are investigated. It is found that barrierless oxygen dissociation occurs on the (111) facet of the pure platinum clusters. A barrier of $\sim 0.3 \mathrm{eV}$ is observed on the (100) facet. For the alloyed cluster, dissociation barriers are found on both facets, typically $\sim 0.6 \mathrm{eV}$. The differences between the two systems are attributed to the ability of oxygen to distort the (111) surface of the pure platinum clusters. We show that flexibility of the platinum shell is crucial in promotion of fast oxygen dissociation. However, the titanium core stabilises the platinum shell upon alloying, resulting in a less easily distortable surface. Therefore, whilst an alloyed platinum-titanium electrocatalyst has certain advantages over the pure platinum electrocatalyst, we suggest alloying with a more weakly interacting metal will be beneficial for facilitating oxygen dissociation.

Received 5th September 2013 Accepted 13th November 2013

DOI: $10.1039 / c 3 n r 04750 d$

www.rsc.org/nanoscale layers, the carbonaceous electronic conductor-gas diffusion layer, the polymer electrolyte membrane and the reactants (hydrogen and oxygen)..$^{21,22}$

Another serious problem with PEFCs is that the hydrogen feed usually contains significant amounts of carbon monoxide (CO), which poisons the Pt electrocatalyst. Alloying Pt to reduce loading and improve catalytic characteristics such as performance, durability and reactivity is a promising approach. We previously reported the results of theoretical calculations which suggested that alloying Pt with titanium (Ti), a much cheaper transition metal (£0.28 per ounce as of 10/07/13), to form Ti@Pt core-shell clusters (Ti - core, Pt shell), results in weaker binding of hydroxyl $(\mathrm{OH})$ and $\mathrm{CO}$ with reduced Pt loading. ${ }^{23}$ Weaker binding of $\mathrm{OH}$ can lead to improvements in ORR kinetics, while weakening of $\mathrm{CO}$ binding lessens poisoning effects. Weaker adsorption was attributed to changes in the electronic structure attained through alloying; specifically, changes in the $d$-band centre. ${ }^{24}$ At the same time the catalyst has to facilitate the initial stage of ORR, namely $\mathrm{O}_{2}$ dissociation.

In our present work, oxygen dissociation is studied on pure Pt clusters as well as core-shell Ti@Pt clusters. Dissociation on the (111) slab model is also included, as this can represent the process on (111) terraces of larger particles. Initially focusing on 38 atom clusters, barrier-free dissociation is observed for the $\mathrm{Pt}_{38}$ cluster on the (111) facet. However, notable dissociation barriers are observed for the (100) facet as well as both (111) and (100) facets on the $\mathrm{Pt}_{32} \mathrm{Ti}_{6}$ cluster. This behaviour is explained through an in depth study of cluster stability and is further investigated for 79 atom clusters.
UK

${ }^{b}$ Departament de Quimica Física \& IQTCUB, Universitat de Barcelona, Spain

${ }^{c}$ Faculty of Chemistry and Pharmacy, University of Sofia, Sofia, Bulgaria

${ }^{d}$ Institució Catalana de Recerca i Estudis Avançats (ICREA), Barcelona, Spain

${ }^{e}$ School of Chemistry, University of Birmingham, Edgbaston, Birmingham, UK. E-mail: r.l.johnston@bham.ac.uk; Fax:+44 (o)121 414 4403; Tel: +44 (0) 1214147477

$\dagger$ Electronic supplementary information (ESI) available. See DOI: $10.1039 / \mathrm{c} 3 \mathrm{nr} 04750 \mathrm{~d}$ 


\section{Methodology}

Calculations are performed using the Vienna $A b$ initio Simulation Package (VASP) $5.2 .^{25-28}$ The $5 \mathrm{~d}^{9} 6 \mathrm{~s}^{1}$ of Pt, $3 \mathrm{~d}^{3} 4 \mathrm{~s}^{1}$ of Ti and $2 \mathrm{~s}^{2} 2 \mathrm{p}^{4}$ of $\mathrm{O}$ are treated as valence electrons, while the ionic cores are represented by the projected augmented wave (PAW) method. ${ }^{29,30}$ Electronic exchange and correlation are described using the generalised gradient approximation (GGA) using the Perdew Wang 91 (PW91) functional. ${ }^{31,32}$ The Methfessel-Paxton smearing method is used with a width of $0.1 \mathrm{eV}$ (extrapolated for computing final energies to zero smearing) and an energy cutoff of $415 \mathrm{eV}$ is employed. DFT-D calculations were also performed on a number of test cases, although the inclusion of van der Waals forces through the empirical treatment of Grimme results in little change and so was not considered in the following results.

The bulk systems were modelled by five layers of repeated $3 \times 3$ (111) slabs, allowing the top two layers of the Pt(111) slab to relax fully while fixing the bottom 3 layers. A $5 \times 5 \times 1 k$ point mesh was used to sample the first Brillouin zone. Approximately $10 \AA$ of vacuum was included between neighbouring systems. For the cluster systems, 38 and 79 atom clusters were considered, these are magic numbers leading to complete Truncated Octahedral (TO) structures. The clusters are placed in the centre of a large enough supercell to ensure sufficient separation $(\sim 10 \AA)$ between periodic images, the $\Gamma$ point is used to sample the Brillouin zone. All atoms are relaxed according to the calculated atomic forces, with convergence criteria for total energies $1.0 \times 10^{-4} \mathrm{eV}$ and forces required to be less than $0.02 \mathrm{eV}^{-1}$.

In order to assess the (atomic or molecular) oxygen adsorption strength to the Pt surface, the binding energy $\left(E_{\mathrm{b}}\right)$ is calculated, as defined in eqn (1).

$$
E_{\mathrm{b}}=E_{\mathrm{AB}}-\left(E_{\mathrm{A}}+E_{\mathrm{B}}\right)
$$

$E_{\mathrm{AB}}$ is the energy of the cluster with oxygen adsorbed, $E_{\mathrm{A}}$ is the energy of the relaxed cluster and $E_{\mathrm{B}}$ is the energy of the free oxygen atom or molecule, negative $E_{\mathrm{b}}$ values imply favourable binding. The interaction energy $\left(E_{\text {int }}\right)$ is defined in eqn (2).

$$
E_{\text {int }}=E_{\mathrm{AB}}-\left(E_{\mathrm{A}}^{*}+E_{\mathrm{B}}^{*}\right)
$$

The single point energies of species distorted upon adsorption are denoted by *, again negative values imply favourable interactions. Distortion energies can be calculated using eqn (3) for $\mathrm{Pt}_{n-m} \mathrm{Ti}_{m}$ (where $n=38,79$ and $m=0,6,19$ ) and eqn (4) for oxygen distortions.

$$
\begin{gathered}
\Delta E\left(\mathrm{Pt}_{n-m} \mathrm{Ti}_{m}\right)=E\left(\mathrm{Pt}_{n-m} \mathrm{Ti}_{m}\right)-E\left(\mathrm{Pt}_{n-m} \mathrm{Ti}_{m}\right)^{*} \\
\Delta E\left(\mathrm{O}_{2}\right)=E\left(\mathrm{O}_{2}\right)-E\left(\mathrm{O}_{2}\right)^{*}
\end{gathered}
$$

Although specific distortions, brought about by adsorption of oxygen, are discussed in detail, as a more general measure root mean squared displacements (RMSD) of atoms are calculated. RMSD is calculated as defined in eqn (5).

$$
R M S D=\sqrt{\left(\frac{1}{N} \sum_{i=1, N} M_{i}-M_{i}^{*}\right)^{2}}
$$

$N$ is the total number of atoms, $M_{i}$ is the position of a given atom (between 1 and $\mathrm{N}$ ) for the relaxed bare cluster and $M_{i}^{*}$ is the position of the same atom in the cluster following oxygen adsorption. Prior to applying this equation, a rotation and translation operator is used to align each cluster, thereby minimising the RMSD.

Dissociation pathways were investigated using the VASP Transition State Tools (VTST) implementation by the Henkelman Group, first generating an approximate pathway using the Nudged Elastic Band (NEB) method, ${ }^{33}$ with further refinements achieved using the Dimer method. ${ }^{34}$ Bader charge analysis ${ }^{35}$ was performed using the Bader code ${ }^{36}$ also from the Henkelman Group.

\section{Results and discussion}

\subsection{Slab model}

Large metal nanoparticles are often approximated in computational studies of catalysts by infinite slab models of (111) surface. ${ }^{37}$ Hence, we start our study investigating $\mathrm{O}_{2}$ dissociation on slabs. There are four non-symmetry equivalent sites on the surface of the infinite (111) slab, the atop, bridge, $f c c$ and $h c p$ sites. It is found that the bridge and $f c c$ sites are energetically competitive, the $E_{\mathrm{b}}$ for $\mathrm{O}_{2}$ at the bridge site being $-0.87 \mathrm{eV}$, while it is $-0.86 \mathrm{eV}$ for the $f c c$ position. This is in good agreement with experimental and theoretical studies, which have found both sites favourable for $\mathrm{O}_{2}$ chemisorption. ${ }^{38-42}$ The $h c p$ site is $0.1 \mathrm{eV}$ higher in energy than the $f c c$ site (at $-0.76 \mathrm{eV}$ ), while migration occurs when locally minimising $\mathrm{O}_{2}$ at the atop position, resulting in $\mathrm{O}_{2}$ bonding to the more favourable $f c c$ site.

For the Pt(111) system, the oxygen molecule is initially adsorbed on a three-fold $f c c$ hollow site, before dissociating resulting in each $\mathrm{O}$ atom being bound to $f c c$ hollow sites. The dissociation barrier on the $\mathrm{Pt}(111)$ slab is found to be $0.45 \mathrm{eV}$, in agreement with other calculations, which find a barrier of between 0.4 and $0.6 \mathrm{eV}$, presented in the literature $\mathrm{e}^{\mathbf{1 , 5 , 4 3 - 4 5}}$ as well as experimental studies. ${ }^{46}$ An O-O distance of $2.10 \AA$ is found at the transition state (TS) structure, this compares to an O-O distance of $1.40 \AA$ for the initial state (IS) and $1.24 \AA$ in the gas phase $\mathrm{O}_{2}$. Significant elongation of the $\mathrm{O}-\mathrm{O}$ bond suggests a late transition state. The average Pt-Pt bond lengths in the $f c c$ sites below the adsorbate for the IS, TS and final state (FS) structures are close 2.94, 2.98 and $2.97 \AA$, respectively. However, the average Pt-Pt bond lengths for the pure Pt(111) surface is found to be $2.82 \AA$ for the $f c c$ hollow. This shows slight elongation of the Pt-Pt bond length when $\mathrm{O}_{2}$ is adsorbed, by $\leq 0.15 \AA$. This is reflected in the relatively low RMSD values of $0.03,0.05$ and $0.05 \AA$, respectively, for IS, TS and FS structures. It is expected that a shortening of the Pt-O bond will be observed, corresponding to increased interactions with the Pt surface as $\mathrm{O}_{2}$ dissociates. Indeed, average $\mathrm{Pt}-\mathrm{O}$ bond lengths are 2.14, 1.95 and $2.05 \AA$ for the IS, TS and FS, respectively.

The distortion energy of the bulk slab $\left(\Delta E\left(\mathrm{Pt}_{\text {surf }}\right)\right)$ is found to be $0.17,0.25$ and $0.39 \mathrm{eV}$ for the IS, TS and FS, respectively. Greater distortion of the surface is generally expected as the system progresses from the IS to the FS due to greater $\mathrm{Pt}-\mathrm{O}$ interactions and a reduction in $\mathrm{O}-\mathrm{O}$ interactions. $\Delta E\left(\mathrm{O}_{2}\right)$ values calculated for the IS, TS and FS are $0.64,5.72$ and $6.34 \mathrm{eV}$, respectively. The average charge on the Pt atoms directly below $\mathrm{O}_{2}$ is $+0.18,+0.34$ 
and $+0.29|\mathrm{e}|$ for the IS, TS and FS. While overall average charges on $\mathrm{O}_{2}$ are $-0.34,-0.57$ and $-0.76|\mathrm{e}|$ for the IS, TS and FS, respectively. For all states, electron density is withdrawn from Pt by $\mathrm{O}$, with increased charge transfer as the system progresses form the IS to the FS. There is greater Pt charge transfer when comparing the TS to the FS, this is due to $\mathrm{O}_{2}$ being bonded to one 3-fold $f c c$ hollow site at the TS and two at the FS.

We also considered PtTi (111) alloyed system, with a model (which has been studied before ${ }^{47}$ ) where the second layer of the slab was set as Ti and the top three layers (Pt-Ti-Pt) were allowed to fully relax. During the geometry optimization, however it shows instability and surface and subsurface layers can no longer be identified as (111). In order to study a more realistic model of the PtTi(111) alloyed system, we considered Ti@Pt nanoparticles, with Ti cores, where the effect of edges, larger flexibility, etc. can be taken into account. We studied two model clusters consisting of 38 and 79 metal atoms.

\subsection{Atom clusters}

3.2.1 Oxygen adsorption. On the surface of the 38 atom TO cluster there are eight symmetry inequivalent sites for a pure surface composition of the monometallic and alloyed core-shell clusters, shown in Fig. 1. Adsorption studies of atomic and molecular oxygen are performed on all non-symmetry equivalent sites. $E_{\mathrm{b}}$ values are then calculated, the results of which can be found in Table 1. Two possible bonding orientations are studied for $\mathrm{O}_{2}$ adsorption, axial and planar. The axial configuration has $\mathrm{O}_{2}$ bound to the surface through one $\mathrm{O}$ atom. The planar configuration is bound parallel to the surface, where the adsorbate position is defined in the following by the position of the middle of the $\mathrm{O}-\mathrm{O}$ bond. It is found that the planar conformation is favourable in all cases, hence only those values are listed in Table 1.

For the pure $\mathrm{Pt}_{38}$ cluster, three-fold hollow positions 6 and 7 on the (111) facets, as well as the edge bridge position 5 between the (111) and (100) facets are the most stable for adsorption of atomic oxygen, $-5.21,-5.12$ and $-5.12 \mathrm{eV}$, respectively. Interestingly, on $\mathrm{Pt}_{32} \mathrm{Ti}_{6}$, three-fold hollow positions are no longer locally stable and move to bridge sites ( 4 and 5 ). Position 5 is the most stable site, with an $E_{\mathrm{b}}$ value of $-4.78 \mathrm{eV}$, a decrease of $0.34 \mathrm{eV}$ with respect to the same position on the pure $\mathrm{Pt}_{38}$ cluster.

For $\mathrm{O}_{2}$ adsorption, position 5 , the edge-bridge site between (111) and (100) facets is most stable on both $\mathrm{Pt}_{38}$ and $\mathrm{Pt}_{32} \mathrm{Ti}_{6}, E_{\mathrm{b}}$

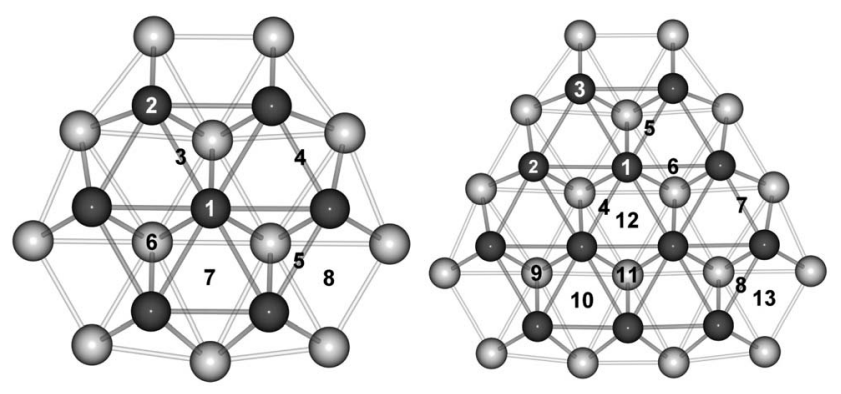

Fig. 1 Top view of the surface (dark grey) and subsurface (light grey) metal atoms at (111) facet sites on the 38 (left) and 79 (right) atom TO clusters.
Table 1 Calculated binding energies $\left(E_{\mathrm{b}}\right)$ for atomic and molecular oxygen on all non-symmetry equivalent sites of the 38 atom clusters, shown in Fig. 1. Values not presented are the result of oxygen migration to other sites during relaxation, as labeled. All energies are given in $\mathrm{eV}$

\begin{tabular}{llllll}
\hline Site & Position & $\mathrm{Pt}_{38}-\mathrm{O}$ & $\mathrm{Pt}_{38}-\mathrm{O}_{2}$ & $\mathrm{Pt}_{32} \mathrm{Ti}_{6}-\mathrm{O}$ & $\mathrm{Pt}_{32} \mathrm{Ti}_{6}-\mathrm{O}_{2}$ \\
\hline 1 & Top & -4.17 & -0.51 & $-{ }^{a}$ & $-{ }^{b}$ \\
2 & Top & -4.48 & -0.77 & -4.16 & -0.59 \\
3 & bridge & $-{ }^{a}$ & -1.66 & $-{ }^{a}$ & -0.57 \\
4 & bridge & -4.72 & -1.67 & -4.39 & -1.02 \\
5 & bridge & -5.12 & -2.01 & -4.78 & -1.75 \\
6 & hcp & -5.21 & -1.84 & $-{ }^{c}$ & -0.73 \\
7 & fcc & -5.12 & -1.80 & $-{ }^{a}$ & -0.37 \\
8 & 4-fold & -4.79 & $-{ }^{c}$ & -4.25 & $-^{c}$
\end{tabular}

${ }^{a}$ Adsorbate migration to position $4 .{ }^{b}$ Adsorbate migration to position 6. ${ }^{c}$ Adsorbate migration to position 5.

values are -2.01 and $-1.75 \mathrm{eV}$, respectively. Hollow positions 6 and 7 are next in stability, -1.84 and $-1.80 \mathrm{eV}$, on $\mathrm{Pt}_{38}$, while on $\mathrm{Pt}_{32} \mathrm{Ti}_{6}$ other bridge positions are more favourable. Edge-bridge sites are also found to be positions of favourable $\mathrm{O}_{2}$ bonding in other studies. Step sites on $\mathrm{Pt}(111)$ surfaces have been reported to result in particularly stable oxygen bonding. ${ }^{\mathbf{4 8 9}}$ Furthermore, studies of Pt TO clusters has revealed favourable bonding at the edge-bridge sites. ${ }^{50}$ Calculations on the $\mathrm{Pt}(100)$ surface have favoured bonding to bridge sites, in line with the results presented here. ${ }^{51}$ As with the previous $\mathrm{OH}$ and $\mathrm{CO}$ adsorption studies, ${ }^{23,24}$ weaker bonding for $\mathrm{O}_{2}$ and $\mathrm{O}$ is calculated for the bimetallic Ti@Pt cluster when compared with the pure Pt cluster.

It is expected that oxygen dissociation will occur preferentially at sites with higher $E_{\mathrm{b}}$ values, where oxygen is most likely to adsorb to the surface of the cluster. Due to the small size of the cluster, it would be relatively easy for molecular oxygen to dissociate and migrate to any of the other seven sites, or an equivalent site in a different location on the surface. It is therefore assumed that dissociation will also likely result in atomic oxygen being adsorbed on the most energetically favourable sites. The energetic ordering of adsorption for molecular oxygen was similar to that of atomic oxygen, making the proposed dissociation pathways relatively straightforward.

The most stable sites, the edge site 5 , as well as hollow sites 6 and 7 are studied. For each pathway, $\mathrm{O}_{2}$ dissociation proceeds from one site to an adjacent position at an equivalent site (e.g. $\mathrm{O}_{2}$ bound to position 5 dissociates to atomic oxygen bound to separate 5 sites). Data for each dissociation pathway is presented in Table 2. In each case, distortion energies of the cluster and $\mathrm{O}_{2}$ at each step of the dissociation pathway are presented.

3.2.2 Distortion and interaction energies. Representations of the minimised geometries for the IS, TS and FS can be found in Fig. S5-S10. $\uparrow$ Studies of the IS show that the distortion energy values $\left(\Delta E\left(\mathrm{Pt}_{n-m} \mathrm{Ti}_{m}\right)\right)$ associated with $\mathrm{Pt}_{38}$ clusters are higher than those for the $\mathrm{Pt}_{32} \mathrm{Ti}_{6}$ clusters. The distortion energies associated with both clusters are also found to be greater than those for the pure slab, in most cases. $\mathrm{O}_{2}$ distortion energies $\left(\Delta E\left(\mathrm{O}_{2}\right)\right)$ show greater distortions of the $\mathrm{O}_{2}$ molecule adsorbed on $\mathrm{Pt}_{38}$ compared with $\mathrm{Pt}_{32} \mathrm{Ti}_{6}$ for the IS structures. However, as 
Table 2 Values for cluster $\left(\Delta E\left(\mathrm{Pt}_{n-m} \mathrm{Ti}_{m}\right)\right)$ and oxygen $\left(\Delta E\left(\mathrm{O}_{2}\right)\right)$ deformation energies, root mean squared displacements (RMSD) of the cluster, interaction energies $\left(E_{\text {int }}\right)$, binding energies $\left(E_{\mathrm{b}}\right)$ and barriers for $\mathrm{O}_{2}$ dissociation $\left(\Delta E^{\neq}\right)$. The ratios of distortion energy to $\mathrm{RMSD}\left(\Delta E\left(\mathrm{Pt} \mathrm{t}_{n-m} \mathrm{Ti}_{m}\right) /\right.$ RMSD) are also presented. Site numbering is introduced in Fig. 1. All energy values are given in eV, RMSD in $\AA$

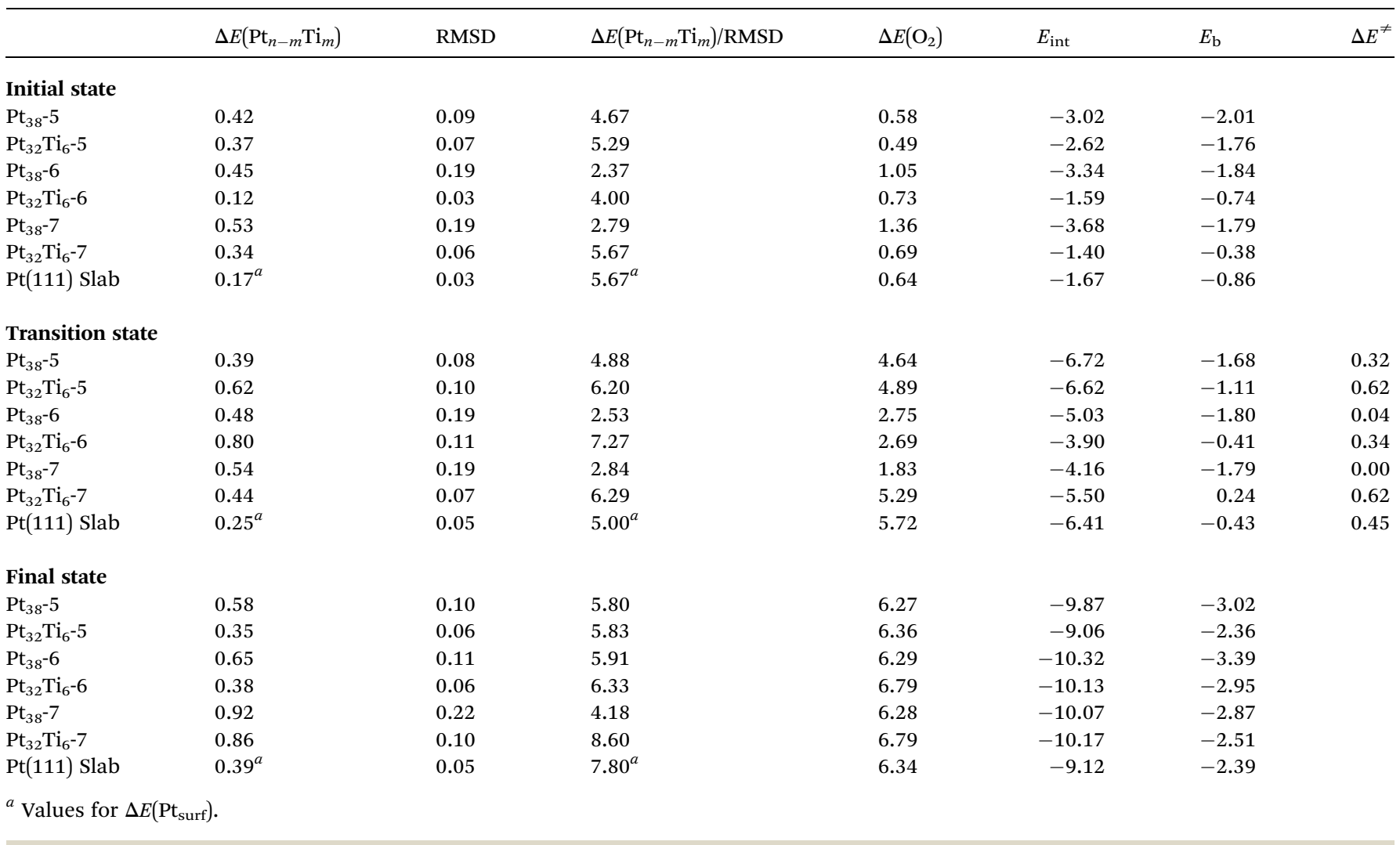

mentioned previously, larger in magnitude adsorption energies are observed for the $\mathrm{Pt}_{38}$ clusters compared to the $\mathrm{Pt}_{32} \mathrm{Ti}_{6}$ clusters. This suggests that the increased interaction energy of $\mathrm{O}_{2}$ to the $\mathrm{Pt}$ surface of the pure cluster, overcomes the distortion energies to a greater extent than for the bimetallic clusters. Furthermore, the stronger Pt-O binding will likely aid in distorting both oxygen and the $\mathrm{Pt}_{38}$ cluster to a greater degree than the $\mathrm{Pt}_{32} \mathrm{Ti}_{6}$ cluster. $\Delta E\left(\mathrm{O}_{2}\right)$ values calculated for the bulk system are found to be greater than those on the (100) facet of both clusters, however smaller than on the (111) facet. The greater distortions on the cluster (111) facets compared to those on the slab are likely due to the increased binding energies on the clusters.

Distortion energies in the TS structures show, in general, that there is a greater distortion energy associated with the $\mathrm{Pt}_{32} \mathrm{Ti}_{6}$ clusters. The one exception is where distortion occurs on site 7 of the $\mathrm{Pt}_{32} \mathrm{Ti}_{6}$ cluster, due to different types of TS structures. In this case, a "straight" dissociation pathway is located over the central atop position (site 1 ) of the $\mathrm{Pt}_{32} \mathrm{Ti}_{6}$ cluster. For dissociation on site 6 , however, a more curved pathway is preferred, avoiding the atop position and instead progressing over the hollow sites of the alloyed cluster. However, the fact that the distortion energies for the $\mathrm{Pt}_{32} \mathrm{Ti}_{6}$ clusters are significantly higher than for the $\mathrm{Pt}_{38}$ clusters suggests that the presence of the Ti core in the alloyed cluster stabilises (makes more rigid) the Pt shell. Nevertheless, the alloyed cluster is still distorted by the adsorbate. In all cases, the cluster distortion energies are greater than that of the slab, suggesting that the slab is significantly harder to distort than both clusters at the TS leading to little change in the slab structure. Similar to IS, data for the FS show the distortion energies associated with the $\mathrm{Pt}_{38}$ clusters are higher than those for the alloyed $\mathrm{Pt}_{32} \mathrm{Ti}_{6}$ clusters in all cases. Once again, there is generally greater distortion energies associated with the clusters than the slab. This was found to be the case also for positions 5 and 6 .

For the pure Pt clusters, the IS and TS have similar distortion energies, the FS is found to have slightly greater distortion energies. This is consistent with atomic oxygen having a greater effect on the Pt surface than the single $\mathrm{O}_{2}$ molecule. For the $\mathrm{Pt}_{32} \mathrm{Ti}_{6}$ clusters, it is found that the TS generally has greater distortion energies than the IS or FS. The exception to this is dissociation occurring at position 7 , where a relatively small distortion energy is found at the TS compared to a relatively high energy at the FS. In summary, this energetic ordering suggests that at sites 5 and 6 greater distortions occur at the TS, not the FS as with the pure Pt clusters.

RMSD of the metal atoms are also listed in Table 2, it is important to note that $\mathrm{O}_{2}$ distortions are not accounted for. These indicate the geometric distortion of the metal particle due to adsorption of the $\mathrm{O}_{2}$ molecule. Data on distortions to specific facets of the cluster are described later. For RMSD analysis, the geometry of the distorted cluster, with $\mathrm{O}_{2}$ removed, is compared to the geometry of the relaxed gas phase cluster, with higher values suggesting greater distortion. For the $\mathrm{Pt}_{38}$ clusters, there is a larger RMSD associated with $\mathrm{O}_{2}$ adsorption 
on the (111) facet, compared to the (100) facet, an average of 0.19 and $0.09 \AA$, respectively. For the $\mathrm{Pt}_{32} \mathrm{Ti}_{6}$ clusters, there is less difference between $\mathrm{O}_{2}$ adsorption on the (111) and (100) facets, $0.03-0.11 \AA$ $v s$. 0.06-0.10 A. Furthermore, it is found that smaller RMSD values for the bimetallic clusters can lead to greater distortion energies compared to the pure Pt clusters. This shows that even though there is less overall distortion, there is a greater energetic cost associated with it for the $\mathrm{Pt}_{32} \mathrm{Ti}_{6}$ clusters. This is expected, as the $\mathrm{Pt}_{2}$ dimer binding energy is found to be $-4.11 \mathrm{eV}$, which is destabilised over both the PtTi and $\mathrm{Ti}_{2}=$ dimers, -6.08 and $-5.34 \mathrm{eV}$, respectively. Comparing to the values calculated for the bulk system ( RMSD $<0.05)$, there are significantly greater RMSD values associated with the $\mathrm{Pt}_{38}$ clusters and marginally greater values for the $\mathrm{Pt}_{32} \mathrm{Ti}_{6}$ cluster.

$\Delta E\left(\mathrm{Pt}_{n-m} \mathrm{Ti}_{m}\right) / \mathrm{RMSD}$ has been calculated, showing the energy needed to achieve RMSD of $1.00 \AA$. An average of 1.71 , 3.17 and $1.63 \mathrm{eV} \AA^{-1}$ more energy is required to distort the $\mathrm{Pt}_{32} \mathrm{Ti}_{6}$ cluster, than the $\mathrm{Pt}_{38}$ cluster at the IS, TS and FS, respectively. This demonstrates the significant energy barriers that need to be overcome in order to distort the $\mathrm{Pt}_{32} \mathrm{Ti}_{6}$ cluster compared to the $\mathrm{Pt}_{38}$ cluster.

A high dissociation barrier $\left(\Delta E^{\neq}\right)$is found for site 5 , on the (100) facet of the $\mathrm{Pt}_{32} \mathrm{Ti}_{6}$ cluster, $0.62 \mathrm{eV}$, this being approximately twice that of the pure $\mathrm{Pt}_{38}$ cluster, $0.32 \mathrm{eV}$ (Table 2). When considering the (111) facet of the $\mathrm{Pt}_{32} \mathrm{Ti}_{6}$ cluster, the dissociation barriers for sites 7 and 5 are equal, $0.62 \mathrm{eV}$, while for site 6 the barrier, $0.34 \mathrm{eV}$, is about half that of the other two sites. The $\mathrm{Pt}_{38}$ cluster is found to exhibit barrier-free dissociation on the (111) facet, this dramatically differs to the $0.45 \mathrm{eV}$ barrier found on the $\mathrm{Pt}(111)$ slab. On the (100) facet of the $\mathrm{Pt}_{38}$ cluster (site 5), comparable dissociation barriers are found to site 6 on the $\mathrm{Pt}_{32} \mathrm{Ti}_{6}$ cluster.

3.2.3 Geometric analysis. Analysis of the system geometries can be found in Table 3. O-O bonds, in general, are shorter for the IS adsorption on the (100) facet. However, at the TS, generally shorter bond lengths are associated with the (111) facet. When studying the average $\mathrm{Pt}-\mathrm{O}$ bond length, as the system moves from the IS to the TS, the average bond length gets smaller. The average Pt-Pt bond lengths are found to be 2.65, 2.70 and 2.70 $\AA$ for bond types 1 to 3, respectively (Fig. 2) for the bare $\mathrm{Pt}_{38}$ cluster, while for the bare $\mathrm{Pt}_{32} \mathrm{Ti}_{6}$ cluster, the corresponding Pt-Pt bond lengths are slightly larger, 2.69, 2.71 and $2.74 \AA$ for sites 1 to 3 , respectively.
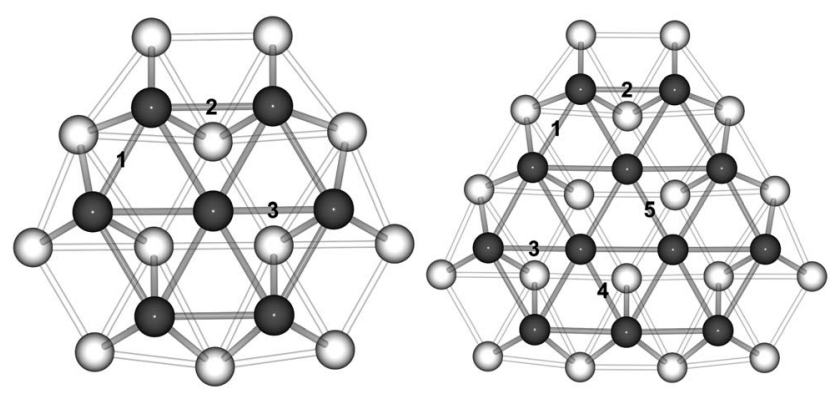

Fig. 2 Bond numbering on the 38 (left) and 79 atom (right) TO clusters.
Once oxygen is adsorbed on the (100) facet of the $\mathrm{Pt}_{38}$ cluster, significant elongation of bond type 2 by up to $0.54 \AA$ is observed, although there is less overall distortion of the cluster geometry. Following oxygen adsorption on the (100) facet, the average distortion of the Pt-Pt bonds calculated from the data in Table 3 is $0.43,0.53$ and $0.78 \AA$ for sites 5,6 and 7 on the $\mathrm{Pt}_{38}$ cluster, respectively. When $\mathrm{O}_{2}$ is adsorbed on the (111) facet, there is a slight elongation of bond type 1 by up to $0.29 \AA$, although not as much as for bond type 3 by up to $0.85 \AA$, which is significantly elongated. There is generally a slight contraction in the bond length of type 2 by up to $0.06 \AA$. This suggests that the majority of the distortion that occurs when $\mathrm{O}_{2}$ is adsorbed on the (111) facet of the $\mathrm{Pt}_{38}$ cluster is due to changes in the bond length of type 3 , bonding to the central (111) atom. For the $\mathrm{Pt}_{32} \mathrm{Ti}_{6}$ cluster significant elongation is observed of bond type 2 by up to $0.57 \AA$, when $\mathrm{O}_{2}$ is adsorbed on site 5 of the (100) facet. However, there is considerably less distortion of the other bond types when $\mathrm{O}_{2}$ is adsorbed on the (111) facet, the maximum distortion observed being $\leq 0.37 \AA$.

$\mathrm{Pt}-\mathrm{X}^{\text {centre }}$ values are only calculated for dissociations on the (111) facet. From the values presented in Table 4, there are few well-defined trends when comparing initial, transition and final states. However, the point of these values is to demonstrate the differences between the $\mathrm{Pt}_{38}$ and $\mathrm{Pt}_{32} \mathrm{Ti}_{6}$ clusters. $\mathrm{Pt}-\mathrm{X}^{\text {centre }}$ was calculated by defining a plane through the cluster, parallel to the (111) facet on which oxygen is adsorbed and then measuring Pt distortions along the $y$-axis from that plane. The plane passes through the central atoms of the (111) surfaces surrounding the facet on which the $\mathrm{O}_{2}$ is adsorbed, as shown in Fig. 3.

Following $\mathrm{O}_{2}$ adsorption, $\mathrm{Pt}-\mathrm{X}^{\text {centre }}$ distances are presented in Table 4. This reveals small distortions, $\leq 0.14$ and $\leq 0.08 \AA$ for the $\mathrm{Pt}_{38}$ and $\mathrm{Pt}_{32} \mathrm{Ti}_{6}$ clusters, respectively, measuring distances from the plane to the bottom of the cluster. More significant changes are seen at the top of the cluster, $\leq 0.91$ and $\leq 0.42 \AA$ for the $\mathrm{Pt}_{38}$ an $\mathrm{Pt}_{32} \mathrm{Ti}_{6}$ clusters, respectively. Furthermore, it is found that there is considerably stronger distortion of the $\mathrm{Pt}_{38}$ cluster, with the atop central (111) atom being pulled out of the plane. The relationship between $\mathrm{Pt}-\mathrm{X}^{\text {centre }}$ and distortion barriers can be seen in Fig. $\mathrm{S} 1$ and $\mathrm{S} 2 \uparrow$ for the IS and TS.

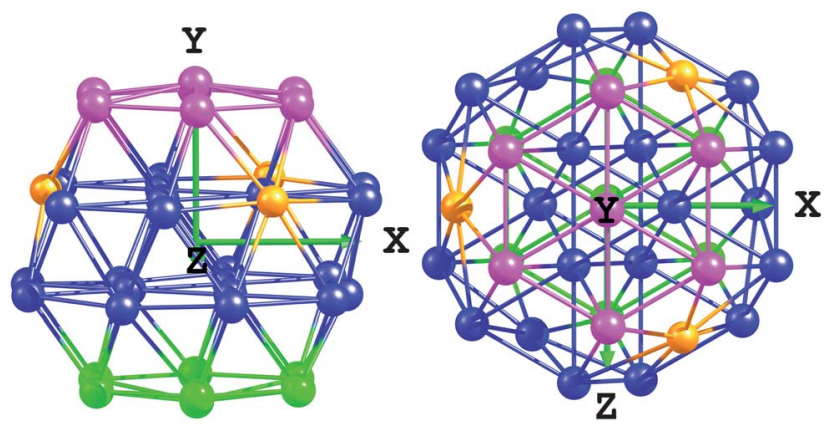

Fig. 3 Splitting the cluster into top and bottom portions to analyse relevant movement of the plane defined to measure distortions. Pink atoms are at the top of the cluster, whilst green are at the bottom. The plane passes through the centre of the adjoining (111) surfaces to that at which the $\mathrm{O}_{2}$ is adsorbed, in this case depicted by the orange atoms. 
Table 3 Data for oxygen-oxygen distances (O-O), average platinum-oxygen bond lengths (Pt-O), average platinum-platinum bond lengths $(\mathrm{Pt}-\mathrm{Pt})$ for specific bonds defined in Fig. 2 and distances from the octahedral core to the central (111) atom in the $y$-direction (Pt-Xentre). Average $\mathrm{Pt}-\mathrm{Pt}$ bond lengths are calculated for those atoms directly below the adsorbed $\mathrm{O}_{2}$ molecule. The type of the bond is shown in brackets according to Fig. 2. All values are given in $\AA$

\begin{tabular}{|c|c|c|c|c|c|c|c|c|c|c|c|c|}
\hline & \multicolumn{3}{|l|}{$\mathrm{O}-\mathrm{O}$} & \multicolumn{3}{|l|}{$\mathrm{Pt}-\mathrm{O}$} & \multicolumn{3}{|l|}{$\mathrm{Pt}-\mathrm{Pt}$} & \multicolumn{3}{|c|}{$\mathrm{Pt}-\mathrm{X}^{\text {centre }}$} \\
\hline & IS & TS & FS & IS & TS & FS & IS & TS & FS & IS & TS & FS \\
\hline $\mathrm{Pt}_{38^{-}} 5$ & 1.39 & 1.92 & 2.89 & 1.95 & 1.82 & 1.95 & $3.24^{[2]}$ & $3.20^{[2]}$ & $2.94^{[2]}$ & - & - & - \\
\hline $\mathrm{Pt}_{32} \mathrm{Ti}_{6}-5$ & 1.37 & 1.96 & 3.02 & 1.98 & 1.83 & 1.98 & $3.26^{[2]}$ & $3.28^{[2]}$ & $2.93^{[2]}$ & - & - & - \\
\hline $\mathrm{Pt}_{38}-6$ & 1.45 & 1.66 & 3.32 & 2.07 & 2.00 & 2.07 & $\begin{array}{l}2.64^{[2]} \\
3.43^{[3]}\end{array}$ & $\begin{array}{l}2.65^{[2]} \\
3.44^{[3]}\end{array}$ & $\begin{array}{l}2.69^{[2]} \\
2.93^{[3]}\end{array}$ & 3.27 & 3.26 & 2.95 \\
\hline $\mathrm{Pt}_{32} \mathrm{Ti}_{6}-6$ & 1.41 & 1.66 & 5.43 & 2.21 & 2.13 & 1.98 & $\begin{array}{l}2.92^{[2]} \\
2.74\end{array}$ & $\begin{array}{l}3.02^{[2]} \\
3.04^{[3]}\end{array}$ & $2.94^{[2]}$ & 2.19 & 2.72 & 2.08 \\
\hline $\mathrm{Pt}_{38}-7$ & 1.49 & 1.55 & 3.42 & 2.05 & 2.02 & 1.94 & $\begin{array}{l}2.68^{[1]} \\
3.54^{[3]}\end{array}$ & $\begin{array}{l}2.69^{[1]} \\
3.55^{[3]}\end{array}$ & $\begin{array}{l}2.95^{[1]} \\
2.98^{[3]}\end{array}$ & 3.27 & 3.26 & 3.35 \\
\hline $\mathrm{Pt}_{32} \mathrm{Ti}_{6}-7$ & 1.40 & 2.03 & 5.47 & 2.19 & 1.99 & 1.95 & $\begin{array}{l}2.78^{[1]} \\
2.78^{[3]}\end{array}$ & $\begin{array}{l}2.93^{[1]} \\
2.79^{[3]}\end{array}$ & $3.06^{[1]}$ & 2.12 & 2.23 & 2.11 \\
\hline
\end{tabular}

Table $4 \mathrm{Pt}-\mathrm{X}^{\text {centre }}$ distances relative to those of the bare clusters. Positive values show atoms being drawn out of the plane, leading to elongation of the cluster in the $y$-direction, whilst negative values show compression of the cluster in the $y$-direction. All values are given in $\AA$

\begin{tabular}{|c|c|c|c|c|c|c|}
\hline & \multicolumn{2}{|l|}{ IS } & \multicolumn{2}{|l|}{ TS } & \multicolumn{2}{|l|}{ FS } \\
\hline & Top & Bottom & Top & Bottom & Top & Bottom \\
\hline $\mathrm{Pt}_{38^{-}} 6$ & 0.83 & 0.13 & 0.82 & 0.14 & 0.51 & 0.14 \\
\hline $\mathrm{Pt}_{32} \mathrm{Ti}_{6}-6$ & -0.12 & 0.07 & 0.42 & 0.04 & -0.23 & 0.08 \\
\hline $\mathrm{Pt}_{38^{-}}-7$ & 0.83 & 0.00 & 0.82 & 0.00 & 0.91 & 0.00 \\
\hline $\mathrm{Pt}_{32} \mathrm{Ti}_{6}-7$ & -0.18 & 0.03 & -0.07 & 0.04 & -0.19 & 0.02 \\
\hline
\end{tabular}

Table 5 Average charges (|e|) of the initial (IS), transition (TS) and final (FS) state structures of $\mathrm{O}_{2}$ dissociation on the 38 atom clusters

\begin{tabular}{|c|c|c|c|c|c|c|c|c|c|}
\hline & \multicolumn{3}{|c|}{ Pt charges ${ }^{a}$} & \multicolumn{3}{|c|}{ Ti charges ${ }^{b}$} & \multicolumn{3}{|c|}{ O charges } \\
\hline & IS & TS & FS & IS & TS & FS & IS & TS & FS \\
\hline $\mathrm{Pt}_{38^{-5}}$ & 0.31 & 0.46 & 0.45 & - & - & - & -0.33 & -0.51 & -0.74 \\
\hline $\mathrm{Pt}_{32} \mathrm{Ti}_{6}-5$ & 0.04 & 0.22 & 0.21 & 1.97 & 1.97 & 1.88 & -0.34 & -0.55 & -0.75 \\
\hline $\mathrm{Pt}_{38^{-}-6}$ & 0.22 & 0.29 & 0.28 & - & - & - & -0.39 & -0.47 & -0.76 \\
\hline $\mathrm{Pt}_{32} \mathrm{Ti}_{6}-6$ & -0.22 & 0.02 & 0.11 & 1.95 & 1.87 & 1.94 & -0.38 & -0.50 & -0.79 \\
\hline $\mathrm{Pt}_{38^{-7}}$ & 0.25 & 0.26 & 0.33 & - & - & - & -0.43 & -0.45 & -0.74 \\
\hline $\mathrm{Pt}_{32} \mathrm{Ti}_{6}-7$ & -0.23 & -0.10 & 0.09 & 1.95 & 1.93 & 1.94 & -0.37 & -0.58 & -0.76 \\
\hline
\end{tabular}

${ }^{a} \mathrm{Pt}$ atoms interacting directly with $\mathrm{O}$ atoms. ${ }^{b} \mathrm{Ti}$ atoms interacting directly with $\mathrm{O}$ bound $\mathrm{Pt}$ atoms.

3.2.4 Bader charge analysis. We previously studied charge transfer between Pt and Ti atoms within core-shell systems. ${ }^{24}$ For reference, the electronegativities of $\mathrm{Pt}$, Ti and $\mathrm{O}$ are 2.28, 1.54 and 3.44 on the Pauling scale, respectively. For the bare clusters, there is significant electron donation from Ti to Pt, which likely results in the strong core-shell interactions that stabilise the Pt surface. The average charges for the $\mathrm{Pt}_{32} \mathrm{Ti}_{6}$ cluster are found to be -0.36 and $+1.94|\mathrm{e}|$ for $\mathrm{Pt}$ and $\mathrm{Ti}$, respectively. Following this, an analysis was performed of the effect of the adsorbate on the atomic charges, as shown in Table 5.
When $\mathrm{O}_{2}$ is adsorbed on the surface of the pure $\mathrm{Pt}_{38}$ cluster, the Pt atoms on which the oxygen is adsorbed have a positive charge +0.22 to $+0.31|\mathrm{e}|$. It is generally found on $\mathrm{Pt}_{38}$ and $\mathrm{Pt}_{32} \mathrm{Ti}_{6}$ clusters, that the Pt becomes more positively charged as the system moves from the initial to final states, while the $\mathrm{O}$ atoms become more negatively charged at the same time. Furthermore, more positive Pt charge values are observed for $\mathrm{O}_{2}$ adsorption on the (100) facet. This charge transfer is found to be comparable between the slab and cluster models. In the case of the $\mathrm{Pt}_{32} \mathrm{Ti}_{6}$ cluster $\mathrm{Pt}$ has positive and negative charges depending on the state of the system, slightly positive $(+0.04|\mathrm{e}|)$ when $\mathrm{O}_{2}$ is adsorbed on the (100) facet and negative on the (111) facet $(-0.22$ to $-0.23|\mathrm{e}|)$. At the same time, charges on the $\mathrm{Ti}$ atoms, which are remote from the adsorbates, do not change notably. They also do not change when the system progresses from IS to FS. Not surprisingly, the charges on the oxygen atoms get significantly more negative as the system progresses from the initial to the final states. This charge seems unaffected by the site at which oxygen is adsorbed, or whether it is the pure or alloyed cluster. Hence, one can conclude that $\mathrm{O}$ atoms have local effects on the withdrawal of electron density from the closest Pt atoms only. When $\mathrm{O}_{2}$ is adsorbed on the (111) facet of the alloyed $\mathrm{Pt}_{32} \mathrm{Ti}_{6}$ nanoparticle, $\mathrm{Pt}$ is found to have a negative charge at the initial state and a positive charge at the final state, while on the (100) facet, the Pt atoms are positive for all states.

3.2.5 Conclusions. There are several conclusions that can be drawn from the 38 atom system. It is possible to see that there are significant differences in the $\mathrm{Pt}_{38}$ and $\mathrm{Pt}_{32} \mathrm{Ti}_{6}$ systems, not only in adsorption energies but also in the way dissociation proceeds. Larger dissociation barriers are observed for the $\mathrm{Pt}_{32} \mathrm{Ti}_{6}$ system. This is to be expected because oxygen is more weakly adsorbed onto the Pt surface of the alloyed cluster, hence the $\mathrm{O}-\mathrm{O}$ bond is less activated and it therefore takes more energy to dissociate the $\mathrm{O}_{2}$ molecule. Furthermore, for the $\mathrm{Pt}_{38}$ cluster, a higher dissociation barrier is observed for the (100) facet whereas for $\mathrm{Pt}_{32} \mathrm{Ti}_{6}$ there are similar barriers on the (111) and (100) facets. Once again, this coincides with the larger values of adsorption energies associated with the (111) facet for the $\mathrm{Pt}_{38}$ system and the (100) facet for the $\mathrm{Pt}_{32} \mathrm{Ti}_{6}$ system. 
Finally, barrier-free dissociation is observed on the (111) facet of the $\mathrm{Pt}_{38}$ cluster which appears to be due to significant distortions of the facet. There are greater energetic costs associated with distorting the $\mathrm{Pt}_{32} \mathrm{Ti}_{6}$ cluster, compared with $\mathrm{Pt}_{38}$ cluster (Table 2). Although according to the cluster geometries there is greater distortion of the $\mathrm{Pt}_{38}$ cluster. This suggests that the presence of the octahedral $\mathrm{Ti}$ core in the $\mathrm{Pt}_{32} \mathrm{Ti}_{6}$ cluster stabilises the Pt shell and makes the structure more rigid, while $\mathrm{Pt}_{38}$ nanoparticle is more flexible and the surface $\mathrm{Pt}$ atoms become more easily distorted, hence more reactive. When compared to the $\mathrm{Pt}(111)$ bulk system, the barrier for $\mathrm{O}_{2}$ dissociation is found to be $0.45 \mathrm{eV}$, however very little distortion of the (111) surface is observed. This supports the suggestion that it is the distortion of the (111) facet on the cluster that leads to barrier-free dissociation.

\subsection{Atom clusters}

3.3.1 Oxygen adsorption. Following the calculations on 38 atom clusters, studies progressed to larger 79 atom TO clusters, considering the pure $\mathrm{Pt}_{79}$ and core-shell $\mathrm{Pt}_{60} \mathrm{Ti}_{19}$ systems. On the surface of the 79 atom TO cluster there are 13 non-symmetry equivalent sites for a pure surface composition, depicted in Fig. 1. As with the 38 atom clusters, studies of these 13 sites are performed, looking at atomic and molecular oxygen. Binding energies are listed in Table 6.

For the pure $\mathrm{Pt}_{79}$ cluster, the hollow site on the (111) facet is no longer as favourable as the edge-bridge sites on the (100) facet for $\mathrm{O}_{2}$ and $\mathrm{O}$ adsorption. However, the site resulting in strongest bonding is the edge-bridge site of the (111) facet, labelled as site 7 . For the $\mathrm{Pt}_{60} \mathrm{Ti}_{19}$ cluster, in all cases, the edgebridge site on the (100) facet results in strongest bonding. This was also the case for $\mathrm{Pt}_{32} \mathrm{Ti}_{6}$.

In a similar fashion to the 38 atom system, $\mathrm{O}_{2}$ dissociation has been investigated at various sites on the (111) and (100) facets of

Table 6 Calculated binding $\left(E_{\mathrm{b}}\right)$ energies for atomic and molecular oxygen on the various sites of the 79 atom clusters. Values which have not been presented are the result of oxygen migration to other sites during relaxation, as labeled. All energies are given in $\mathrm{eV}$

\begin{tabular}{llllll}
\hline Site & Position & $\mathrm{Pt}_{79}-\mathrm{O}$ & $\mathrm{Pt}_{79}-\mathrm{O}_{2}$ & $\mathrm{Pt}_{60} \mathrm{Ti}_{19}-\mathrm{O}$ & $\mathrm{Pt}_{60} \mathrm{Ti}_{19}-\mathrm{O}_{2}$ \\
\hline 1 & Top & $-{ }^{a}$ & $-{ }^{b}$ & -2.69 & $-{ }^{a}$ \\
2 & Top & $-{ }^{c}$ & -0.41 & $-{ }^{c}$ & -0.41 \\
3 & Top & -4.36 & -0.71 & -4.24 & $-{ }^{d}$ \\
4 & Bridge & $-{ }^{e}$ & -1.07 & $-{ }^{c}$ & -0.09 \\
5 & Bridge & $-g$ & -1.45 & $-{ }^{c}$ & -0.77 \\
6 & Bridge & $-g$ & -1.21 & $-{ }^{c}$ & -0.68 \\
7 & Bridge & -5.04 & -1.83 & -4.60 & -1.15 \\
8 & Bridge & -4.94 & -1.81 & -4.93 & -1.85 \\
9 & $h c p$ & -4.93 & -1.13 & $-{ }^{d}$ & -0.71 \\
10 & fcc & -4.98 & -1.39 & $-{ }^{c}$ & -0.69 \\
11 & hcp & -4.74 & -0.99 & -3.79 & -0.63 \\
12 & fcc & -4.93 & -0.88 & -3.32 & 0.07 \\
13 & 4-fold & -4.83 & $-{ }^{d}$ & -4.56 & $-{ }^{c}$ \\
& Hollow & & & &
\end{tabular}

\footnotetext{
${ }^{a}$ Adsorbate migration to position $9{ }^{b}$ Adsorbate migration to position 5 .

${ }^{c}$ Adsorbate migration to position 7. ${ }^{d}$ Adsorbate migration to position 8.

${ }^{e}$ Adsorbate migration to position $12 .{ }^{f}$ Adsorbate migration to position
}

11. ${ }^{g}$ Adsorbate migration to position 10 . the 79 atom clusters $(8,9,10$ and 11 in Fig. 1). Due to the increased size of the (111) facet, it is no longer beneficial to allow dissociation pathways from a certain site to an identical adjacent site, as this would span the entire facet. Following dissociation, any further barriers observed would be due to migration of the oxygen atoms over the surface, which is not the aim of this study. Therefore, for the 79 atom clusters, the pathways on the (111) facet terminate at the central site 12 . As with the 38 atom clusters, dissociation on the edge-bridge site of the (100) facet proceeds from position 8 to two adjacent 8 sites.

The central positions on the (111) facet were also investigated, the hollow site 12 for the $\mathrm{Pt}_{79}$ cluster and site 4 on $\mathrm{Pt}_{60} \mathrm{Ti}_{19}$. However, relatively small $\mathrm{O}_{2}$ binding energies, particularly on the $\mathrm{Pt}_{60} \mathrm{Ti}_{19}$ cluster, are associated with these sites. Hence, finding TS for $\mathrm{O}_{2}$ dissociation proved difficult on these sites. The terrace site is unlikely to be active for oxygen dissociation due to the weaker Pt-O interactions associated with this position. On the 79 atom clusters, the central three-fold hollow site is surrounded by more favourable edge hollow and bridge sites. This means that it is far more likely that $\mathrm{O}_{2}$ dissociation will occur at the edge sites of the facet, where stronger $\mathrm{Pt}-\mathrm{O}$ bonding is observed. Furthermore, low-coordinated edge sites are able to distort to a greater extent (see below) than the central three-fold hollow site, hence facilitating lower barriers to $\mathrm{O}_{2}$ dissociation.

3.3.2 Distortion and interaction energies. Representations of the minimised geometries for the IS, TS and FS can be found in Fig. S11-S18. $\dagger$ Table 7 shows distortion energies, for the cluster and oxygen as well as interaction, binding energies and dissociation barriers. The IS studies reveal slightly greater energetic penalties (by an average of $0.11 \mathrm{eV}$ ) associated with distorting the $\mathrm{Pt}_{79}$ cluster compared to the $\mathrm{Pt}_{60} \mathrm{Ti}_{19}$ cluster. This same trend is observed for the FS, with greater distortion energies located for the $\mathrm{Pt}_{79}$ cluster. These trends were also found for the smaller 38 atom clusters. However, the trends for the TS structures differ from those for the 38 atom clusters. For the 79 atom clusters, sites 8 and 11 result in greater distortion energies associated with the alloyed $\mathrm{Pt}_{60} \mathrm{Ti}_{19}$, whilst for sites 9 and 10, greater distortion energies are associated with $\mathrm{Pt}_{79}$.

As for $\mathrm{Pt}_{38}$, there are greater distortion energies associated with the FS compared to the IS or TS. This once again suggests that the strongly interacting atomic oxygen has a greater ability to distort the $\mathrm{Pt}_{79}$ surface. For $\mathrm{Pt}_{60} \mathrm{Ti}_{19}$, there are greater distortion energies associated with the TS and FS compared to the IS. RMSD analysis demonstrates that for the $\mathrm{Pt}_{79}$ cluster, there is generally least structural distortion when $\mathrm{O}_{2}$ is adsorbed on position 9 on the (111) facet. Although, there is little difference between positions 8 on the (100) facet and 9 on the (111) facet. There is significant distortion of $\mathrm{Pt}_{79}$ when oxygen is adsorbed on sites 10 and 11. As with the 38 atom clusters, there is greater distortion of the pure Pt clusters, compared to the alloyed ones. For $\mathrm{Pt}_{60} \mathrm{Ti}_{19}$, there is generally little difference between the RMSD for the cases when $\mathrm{O}_{2}$ is adsorbed on (111) and (100) facets, suggesting again that Ti@Pt structures are more rigid due to the strong interaction between Ti core and Pt shell.

When comparing the (111) and (100) facets, it is found that the $\mathrm{Pt}_{79}$ cluster distortion energy associated with site 8 on the 
Table 7 Cluster $\left(\Delta E\left(\mathrm{Pt}_{n-m} \mathrm{Ti}_{m}\right)\right)$ and oxygen $\left(\Delta E\left(\mathrm{O}_{2}\right)\right)$ deformation energies, root mean squared displacements (RMSD) of the cluster, interaction energies $\left(E_{\text {int }}\right)$, binding energies $\left(E_{\mathrm{b}}\right)$ of $\mathrm{O}_{2}$ and barrier of $\mathrm{O}_{2}$ dissociation $\left(\Delta E^{\neq}\right)$. The ratios of distortion energy to $\mathrm{RMSD}\left(\Delta E\left(\mathrm{Pt} t_{n-m} \mathrm{Ti}_{m}\right) / \mathrm{RMSD}\right)$ are also presented. All energy values are given in eV, RMSD in $\AA$

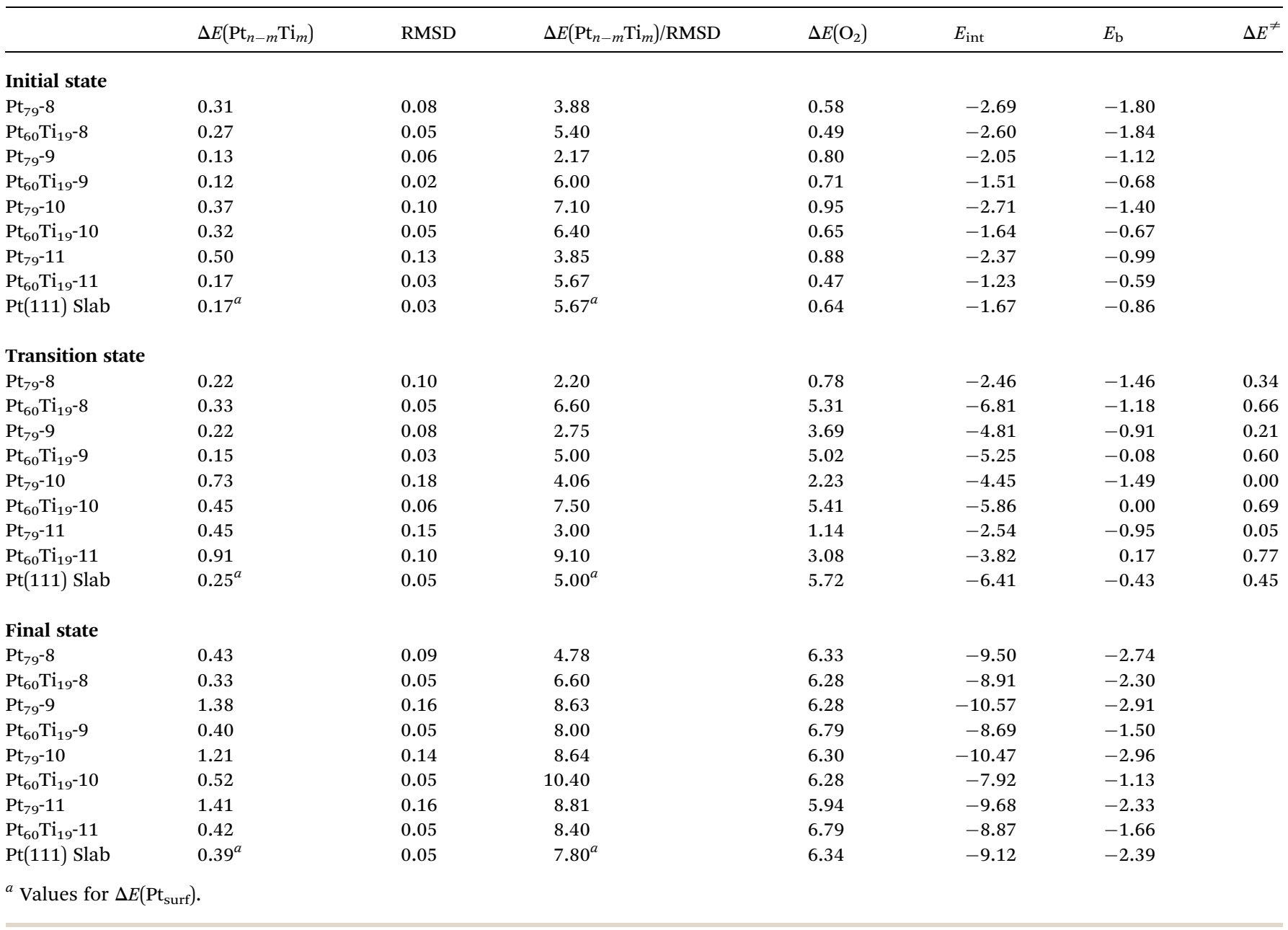

(100) facet is greater than that for site 9 on the (111) facet of the $\mathrm{Pt}_{79}$ IS structure (Table 7). However, the distortion energies become equal at the TS but are $0.95 \mathrm{eV}$ greater on site 9 for the FS structure. For sites 10 and 11 on the (111) facet, the distortion energy is greater than for site 8 in all cases. The $\Delta E\left(\mathrm{Pt}_{79}\right)$ values for sites 9,10 and 11 correlate with the differences between the dissociation barriers between sites. The smallest $\Delta E\left(\mathrm{Pt}_{79}\right)$ value is for site 9 which also has the largest barrier, whilst site 10 has the largest $\Delta E\left(\mathrm{Pt}_{79}\right)$ value and smallest barrier. There is less correlation between cluster distortion energies, surface sites and dissociation barriers for the $\mathrm{Pt}_{60} \mathrm{Ti}_{19}$ system.

$\Delta E\left(\mathrm{Pt}_{n-m} \mathrm{Ti}_{m}\right) / \mathrm{RMSD}$ has also been calculated for the 79 atom clusters. An average of 1.62, 4.05 and $0.64 \mathrm{eV}^{-1}$ more energy is required to distort the $\mathrm{Pt}_{60} \mathrm{Ti}_{19}$ cluster, than the $\mathrm{Pt}_{79}$ cluster at the IS, TS and FS, respectively. This further demonstrates the significant energy barriers that need to be overcome in order to distort the $\mathrm{Pt}_{60} \mathrm{Ti}_{19}$ cluster compared to the $\mathrm{Pt}_{79}$ cluster.

Oxygen distortion values for the IS are greater for the $\mathrm{Pt}_{79}$ system, compared to the $\mathrm{Pt}_{60} \mathrm{Ti}_{19}$ system, in all cases. However, at the TS, significantly greater distortion energies are associated with the $\mathrm{Pt}_{60} \mathrm{Ti}_{19}$ clusters. This suggests that, initially, when oxygen is adsorbed on the surface of the $\mathrm{Pt}_{79}$ cluster, due to the stronger Pt-O interactions, the $\mathrm{O}_{2}$ molecule is distorted to a greater extent than on the alloyed system, where weaker bonding is observed. However, at the TS, on the more weakly bound $\mathrm{Pt}_{60} \mathrm{Ti}_{19}$ system, greater distortion of the $\mathrm{O}_{2}$ molecule is required, compared to the $\mathrm{Pt}_{79}$ system. This greater distortion requires more energy and can rationalise larger dissociation barriers on Ti@Pt compared to the pure Pt nanoparticle. The same discussion is also valid for $\mathrm{Pt}_{38}$ and $\mathrm{Pt}_{32} \mathrm{Ti}_{6}$ nanoparticles. $\mathrm{O}_{2}$ distortion energies correlate with the corresponding $\mathrm{O}-\mathrm{O}$ distances. Furthermore, the smaller difference in the $\mathrm{O}-\mathrm{O}$ distances between the IS and TS for the $\mathrm{Pt}_{79}$ clusters compared to $\mathrm{Pt}_{60} \mathrm{Ti}_{19}$ clusters show that TS are "earlier" on $\mathrm{Pt}_{79}$. Earlier TS are known to have lower barriers, which is found to be the case in this study.

Very similar dissociation barrier on the (100) facet are located for the 79 and 38 atom clusters (Tables 2 and 7). The dissociation barriers are about twice that for the alloyed clusters (0.62 and $0.66 \mathrm{eV}$ for the $\mathrm{Pt}_{32} \mathrm{Ti}_{6}$ and $\mathrm{Pt}_{60} \mathrm{Ti}_{19}$ clusters, respectively) compared to the pure clusters ( 0.32 and $0.34 \mathrm{eV}$ for the $\mathrm{Pt}_{38}$ and $\mathrm{Pt}_{79}$ clusters, respectively). However, for the dissociation barriers located on the (111) facet the relationship becomes a little more complicated. 
Table 8 Data for oxygen-oxygen distances (O-O), average platinum-oxygen bond lengths (Pt-O), average platinum-platinum bond lengths $(\mathrm{Pt}-\mathrm{Pt}$ ) for specific bonds defined in Fig. 2 and distances from the octahedral core to the central (111) atom in the $y$-direction (Pt-Xentre). Average $\mathrm{Pt}-\mathrm{Pt}$ bond lengths are calculated for those atoms directly below the adsorbed $\mathrm{O}_{2}$ molecule. The type of the bond is shown in brackets according to Fig. 2

\begin{tabular}{|c|c|c|c|c|c|c|c|c|c|c|c|c|}
\hline & $\mathrm{O}-\mathrm{O}$ & & & $\mathrm{Pt}-\mathrm{O}$ & & & $\mathrm{Pt}-\mathrm{Pt}$ & & & $\mathrm{Pt}-\mathrm{X}$ & & \\
\hline & IS & TS & FS & IS & TS & FS & IS & TS & FS & IS & TS & FS \\
\hline $\mathrm{Pt}_{79}-8$ & 1.39 & 1.42 & 2.98 & 1.96 & 2.01 & 1.95 & $3.18^{[2]}$ & $3.03^{[2]}$ & $2.96^{[2]}$ & - & - & - \\
\hline $\mathrm{Pt}_{60} \mathrm{Ti}_{19}-8$ & 1.37 & 2.03 & 3.87 & 1.98 & 1.84 & 1.92 & $3.27^{[2]}$ & $3.22^{[2]}$ & $3.04^{[2]}$ & - & - & - \\
\hline $\mathrm{Pt}_{79}-9$ & 1.42 & 1.79 & 3.94 & 2.14 & 2.00 & 2.02 & $\begin{array}{l}2.77^{[2]} \\
2.80^{[3]}\end{array}$ & $\begin{array}{l}2.83^{[2]} \\
2.84^{[3]}\end{array}$ & $\begin{array}{l}2.78^{[2]} \\
2.93^{[3]} \\
3.11^{[5]}\end{array}$ & 3.21 & 3.30 & 4.22 \\
\hline $\mathrm{Pt}_{60} \mathrm{Ti}_{19}-9$ & 1.41 & 1.98 & 5.03 & 2.22 & 2.02 & 2.10 & $\begin{array}{l}2.91^{[2]} \\
2.76^{[3]}\end{array}$ & $\begin{array}{l}2.89^{[2]} \\
2.76^{[3]}\end{array}$ & $\begin{array}{l}2.97^{[2]} \\
2.77^{[5]}\end{array}$ & 2.96 & 3.00 & 2.95 \\
\hline $\mathrm{Pt}_{79}-10$ & 1.44 & 1.60 & 3.17 & 2.08 & 2.00 & 2.04 & $\begin{array}{l}2.72^{[1]} \\
3.54^{[3]} \\
3.53^{[4]}\end{array}$ & $\begin{array}{l}2.72^{[1]} \\
3.54^{[3]} \\
3.54^{[4]}\end{array}$ & $\begin{array}{l}2.74^{[1]} \\
3.12^{[3]} \\
3.19^{[4]} \\
2.98^{[5]}\end{array}$ & 4.01 & 4.01 & 3.93 \\
\hline $\mathrm{Pt}_{60} \mathrm{Ti}_{19}-10$ & 1.40 & 2.05 & 3.75 & 2.18 & 1.99 & 2.02 & $\begin{array}{l}2.69^{[1]} \\
2.85^{[3]} \\
2.90^{[4]}\end{array}$ & $\begin{array}{l}2.72^{[1]} \\
2.77^{[3]} \\
2.91^{[4]}\end{array}$ & $\begin{array}{l}2.70^{[1]} \\
2.75^{[5]}\end{array}$ & 2.92 & 2.96 & 2.91 \\
\hline $\mathrm{Pt}_{79-11}$ & 1.43 & 1.47 & 2.53 & 2.09 & 2.09 & 2.07 & $\begin{array}{l}3.24^{[4]} \\
2.73^{[5]}\end{array}$ & $\begin{array}{l}3.30^{[4]} \\
2.76^{[5]}\end{array}$ & $\begin{array}{l}3.08^{[4]} \\
3.11^{[5]}\end{array}$ & 3.41 & 3.39 & 3.90 \\
\hline $\mathrm{Pt}_{60} \mathrm{Ti}_{19-11}$ & 1.37 & 1.71 & 4.89 & 2.33 & 2.13 & 2.09 & $\begin{array}{l}2.90^{[4]} \\
2.68^{[5]}\end{array}$ & $\begin{array}{l}2.71^{[1]} \\
2.71^{[3]} \\
3.09^{[4]} \\
2.76^{[5]}\end{array}$ & $\begin{array}{l}2.71^{[1]} \\
2.85^{[4]}\end{array}$ & 2.94 & 3.11 & 2.91 \\
\hline
\end{tabular}

For the $\mathrm{Pt}_{38}$ cluster, barrier-free dissociation was observed on sites 6 and 7 on the (111) facet. For the $\mathrm{Pt}_{79}$ cluster, once again almost barrier-free dissociation is located on sites 10 and 11 . However, a dissociation barrier of $0.21 \mathrm{eV}$ is found for dissociation on site 9 . When comparing binding energies at sites 9 and 11, there is a small difference of $0.12 \mathrm{eV}$. Probably this difference is not simply a matter of different Pt-O bonding strengths but is related more to differences in the sites. Sites 9 and 11 are $h c p$ whilst site 10 is $f c c$. This suggests that the difference in dissociation barriers is probably due to the neighbouring surfaces to which the sites are adjacent. Whilst site 9 is neighbouring a (100) facet, sites 10 and 11 both neighbour (111) facets, implying that the adjacent (100) facet distorts less than an adjacent (111) facet and results in the small dissociation barrier for site 9 on the $\mathrm{Pt}_{79}$ cluster (see $\mathrm{Pt}-\mathrm{X}^{\text {centre }}$ values in Table 8). Finally, dissociation barriers on the (111) facet of the $\mathrm{Pt}_{60} \mathrm{Ti}_{19}$ clusters are similar to that of the (100) facet. Here again, correlation between barriers and $\mathrm{Pt}-\mathrm{X}^{\text {centre }}$ values is found since $\mathrm{Pt}-\mathrm{X}^{\text {centre }}$ values are also similar at both types of facets.

3.3.3 Geometric analysis. Again, it appears that the more easily distorted shell on the $\mathrm{Pt}_{79}$ cluster results in the observed barrier-free dissociation. Similar measurements to those performed for the 38 atom clusters, to quantify differences in distortions, are compiled in Table 8. Roughly comparable $\mathrm{O}-\mathrm{O}$ bond lengths are observed for all initial states on the 79 atom clusters, 1.39-1.44 $\AA$ for the pure $\mathrm{Pt}_{79}$ nanoparticle and 1.37$1.41 \AA$ for $\mathrm{Pt}_{60} \mathrm{Ti}_{19}$. At the $\mathrm{TS}$, there are significantly shorter $\mathrm{O}-\mathrm{O}$ bond lengths associated with the $\mathrm{Pt}_{79}$ cluster compared to those for the $\mathrm{Pt}_{60} \mathrm{Ti}_{19}$ clusters, 1.42-1.79 $\AA$ vs. 1.71-2.05 A. Studying $\mathrm{Pt}-\mathrm{O}$ bond lengths reveals a similar trend to those for the 38 atom clusters, where in general, shorter bond lengths are observed as the system progresses from the initial to the transition state.

The Pt-Pt bond lengths for the bare $\mathrm{Pt}_{79}$ cluster are 2.66, 2.73, 2.70, 2.75, $2.68 \AA$ for bond types 1 to 5, respectively (Fig. 2). For site 8 on the (100) facet, significant distortion (by an average of $0.33 \AA$ ) of bond type 2 is observed. However, for the initial and transition states this is unsurprising as $\mathrm{O}_{2}$ is interacting with the one bond. Therefore, although there is significant elongation of bond type 2, there is less overall distortion of the cluster. Bond types 3 and 4 are distorted (by an average of 0.42 and $0.56 \AA$, respectively) to the greatest extent for $\mathrm{O}_{2}$ adsorption on the (111) facet. The elongation of bonds surrounding the hollow sites at which oxygen is adsorbed on the (111) facet leads to greater overall distortions of the cluster.

The Pt-Pt bond lengths of the alloyed $\mathrm{Pt}_{60} \mathrm{Ti}_{19}$ cluster are 2.68, 2.84, 2.73, 2.75 and $2.73 \AA$ for bond types 1 to 5 , respectively. Once again, significant elongation of bond type 2 is observed on the (100) facet when $\mathrm{O}_{2}$ is adsorbed, $0.34 \AA$, although as with the $\mathrm{Pt}_{79}$ cluster, little overall distortion of the cluster is observed, $\leq 0.10 \AA$. There is far less distortion of other bond types when studying dissociation on the (111) facet. This is expected as there appears to be far less distortion of the overall cluster geometries upon adsorbing $\mathrm{O}_{2}$.

$\mathrm{Pt}-\mathrm{X}^{\text {centre }}$ values for the bare pure $\mathrm{Pt}_{79}$ cluster are 3.15 and $6.29 \AA$ for the top and bottom of the cluster, respectively. For the bare $\mathrm{Pt}_{60} \mathrm{Ti}_{19}$ cluster, these values are found to be 3.02 and 6.05 A. Once again, there is considerable distortion of the $\mathrm{Pt}_{79}$ cluster when $\mathrm{O}_{2}$ is adsorbed on the (111) facet, with $\mathrm{Pt}-\mathrm{X}^{\text {centre }}$ distances elongated by up to $1.07 \AA$ (Table 9). There is less distortion of the IS (111) facet (Pt- $\mathrm{X}^{\text {centre }}-0.06 \AA$ ) associated with site 9, where a small dissociation barrier of $0.21 \mathrm{eV}$ is observed. Less 
distortion is also observed for the $\mathrm{Pt}_{60} \mathrm{Ti}_{19}$ clusters, with generally even a slight contraction in the $\mathrm{Pt}-\mathrm{X}^{\text {centre }}$ values. More detailed analysis of the changes in $\mathrm{Pt}-\mathrm{X}^{\text {centre }}$ can be found in Table 9, once again showing little deviation in distances from the plane to the bottom of the cluster. The relationship between $\mathrm{Pt}-\mathrm{X}^{\text {centre }}$ and dissociation barriers can be seen in Fig. S1 and $\mathrm{S} 2 \uparrow$ for the IS and TS, again allowing for further comparisons between the 38 and 79 atom clusters.

3.3.4 Bader charge analysis. Charge analysis is performed, the results of which are given in Table 10. The charges for the bare $\mathrm{Pt}_{60} \mathrm{Ti}_{19}$ cluster are -0.45 and +1.43 for $\mathrm{Pt}$ and $\mathrm{Ti}$ atoms, respectively. For the pure $\mathrm{Pt}_{79}$ cluster, similar to the $\mathrm{Pt}_{38}$ case, a positive charge is found on the Pt atoms interacting with the oxygen. These charges generally get more positive as the system progresses from the initial to final state. Again, this coincides with the charge on the oxygen becoming more negative.

For the $\mathrm{Pt}_{60} \mathrm{Ti}_{19}$ clusters, the charges on the Pt atoms bonded to oxygen generally get less negative as the system progresses from the initial to final state. Only for the dissociation on the (100) facet are the Pt atoms positively charged for both the transition and final states. In all cases, the Ti atoms remain positive, generally gaining greater positive charge than Ti atoms in the bare $\mathrm{Pt}_{60} \mathrm{Ti}_{19}$ nanoparticle. This is consistent with electron donation from $\mathrm{Ti}$ to $\mathrm{Pt}$ which in turn donates to $\mathrm{O}$, following the increase in electronegativity. The situation here differs from that on $\mathrm{Pt}_{32} \mathrm{Ti}_{6}$ cluster, where the charge on the $\mathrm{Ti}$ atoms does not change appreciably when an $\mathrm{O}_{2}$ molecule is

Table $9 \mathrm{Pt}-\mathrm{X}^{\text {centre }}$ values relative to the bare clusters. Positive values show atoms being drawn out of the plane, leading to elongation of the cluster in the $y$-direction, whilst negative values show compression of the cluster in the $y$-direction. All values are given in $\AA$

\begin{tabular}{|c|c|c|c|c|c|c|}
\hline & \multicolumn{2}{|l|}{ IS } & \multicolumn{2}{|l|}{ TS } & \multicolumn{2}{|l|}{ FS } \\
\hline & Top & Bottom & Top & Bottom & Top & Bottom \\
\hline $\mathrm{Pt}_{79^{-9}}$ & 0.06 & -0.07 & 0.15 & -0.11 & 1.07 & -0.12 \\
\hline $\mathrm{Pt}_{60} \mathrm{Ti}_{19^{-9}}$ & -0.06 & 0.01 & -0.02 & 0.01 & -0.07 & -0.01 \\
\hline $\mathrm{Pt}_{79}-10$ & 0.86 & 0.05 & 0.86 & 0.04 & 0.78 & -0.11 \\
\hline $\mathrm{Pt}_{60} \mathrm{Ti}_{19}-10$ & -0.11 & 0.00 & -0.06 & 0.00 & -0.11 & -0.01 \\
\hline $\mathrm{Pt}_{79-11}$ & 0.26 & -0.13 & 0.24 & -0.19 & 0.75 & -0.10 \\
\hline $\mathrm{Pt}_{60} \mathrm{Ti}_{19}-11$ & -0.08 & 0.00 & 0.09 & -0.02 & -0.11 & -0.01 \\
\hline
\end{tabular}

adsorbed. This is likely due to the greater $\mathrm{Ti}$ : Pt ratio when comparing the 79 to the 38 atom clusters. The greater ratio of $\mathrm{Ti}$ : $\mathrm{Pt}$ in the $\mathrm{Pt}_{60} \mathrm{Ti}_{19}$ clusters results in similarly negative charges on the Pt atoms, but smaller positive charges on the $\mathrm{Ti}$ atoms. This will mean that more charge can be drawn from the Ti core as the system progresses to the FS, which would not be possible for the $\mathrm{Pt}_{32} \mathrm{Ti}_{6}$ clusters.

3.3.5 Conclusions. For most of the investigated features of the larger 79 atom clusters, it is possible to see similar trends to the 38 atom clusters. This implies that the present trends can be generalised also to somewhat larger nanoparticles, approaching the size of particles present in common experimental catalytic studies. For the pure $\mathrm{Pt}_{79}$ clusters, essentially barrier-free dissociation barriers are observed on the (111) facet for sites 10 and 11. This coincides with significant distortions of the (111) facet. However, for site 9, less distortion of the (111) facet is observed and a small dissociation barrier of $0.21 \mathrm{eV}$ is found. This difference is attributed to stabilisation effects of the neighbouring (100) facet. As with the 38 atom cluster, a similar dissociation barrier of $0.34 \mathrm{eV}$ is found at site 8 , for the $\mathrm{Pt}_{79}$ and site 5 for the $\mathrm{Pt}_{38}$ models, on the less distorted (100) facet. Once again, dissociation barriers are observed for all sites on the $\mathrm{Pt}_{60} \mathrm{Ti}_{19}$ cluster, which are attributed to a notably more structurally rigid outer Pt shell when the Ti core is present.

\subsection{Nanoparticles vs. slab models}

We found that the three-fold $f c c$ site on the $\operatorname{Pt}(111)$ slab has similar binding energies to the central three-fold $f c c$ site (position 12) on the $\mathrm{Pt}_{79}$ cluster, -0.86 and $-0.88 \mathrm{eV}$, respectively, though, as mentioned previously, position 12 on $\mathrm{Pt}_{79}$ is not favourable for $\mathrm{O}_{2}$ dissociation. It is therefore suggested that the central three-fold $f c c$ site on $\mathrm{Pt}_{79}$ is unlikely to facilitate oxygen dissociation, due to more favourable edge hollow and bridge sites. These sites are absent on the slab Pt(111) model (as no steps or defects are included in the model) it is therefore more likely that dissociation will occur at these three-fold $f c c$ hollow sites, however with a notable barrier of $0.45 \mathrm{eV}$. The rigidity of the bulk slab leads to generally weaker Pt-O bonding compared to the majority of sites on the Pt clusters. However, Pt-O bonding is found to be generally stronger than on the clusters where alloying leads to changes in electronic effects that results

Table 10 Average charges (|e|) of the initial, transition and final states of $\mathrm{O}_{2}$ dissociation on the 79 atom clusters

\begin{tabular}{|c|c|c|c|c|c|c|c|c|c|}
\hline & \multicolumn{3}{|c|}{ Pt charges $^{a}$} & \multicolumn{3}{|c|}{ Ti charges $^{b}$} & \multicolumn{3}{|c|}{ O charges } \\
\hline & IS & TS & FS & IS & TS & FS & IS & TS & FS \\
\hline $\mathrm{Pt}_{60} \mathrm{Ti}_{19}-8$ & -0.03 & 0.19 & 0.11 & 1.87 & 1.86 & 1.83 & -0.33 & -0.59 & -0.74 \\
\hline $\mathrm{Pt}_{79}-9$ & 0.20 & 0.29 & 0.32 & - & - & - & -0.36 & -0.51 & -0.83 \\
\hline $\mathrm{Pt}_{60} \mathrm{Ti}_{19}-9$ & -0.28 & -0.16 & -0.16 & 1.59 & 1.62 & 1.47 & -0.37 & -0.58 & -0.74 \\
\hline $\mathrm{Pt}_{79-11}$ & 0.24 & 0.24 & 0.41 & - & - & - & -0.37 & -0.40 & -0.79 \\
\hline $\mathrm{Pt}_{60} \mathrm{Ti}_{19}-11$ & -0.39 & -0.22 & -0.15 & 1.25 & 1.35 & 1.47 & -0.34 & -0.50 & -0.78 \\
\hline
\end{tabular}

${ }^{a} \mathrm{Pt}$ atoms interacting directly with $\mathrm{O}$ atoms. ${ }^{b} \mathrm{Ti}$ atoms interacting directly with $\mathrm{O}$ bound $\mathrm{Pt}$ atoms. 
in the weaker boding, as discussed earlier. Hence, the dissociation barrier on the slab model is found to lie in between the Pt clusters, with low dissociation barriers coupled with stronger Pt-O bonding, and the Ti@Pt clusters with higher dissociation barriers and weaker Pt-O bonding.

\subsection{Surface flexibility}

From the discussion in subsections 3.2.3 and 3.3.3, we suggest that surface flexibility has a profound effect on the potential of catalysts to activate $\mathrm{O}_{2}$ dissociation. It is therefore of interest that $\mathrm{Pt}(111)$ surface lacks the ability to distort and therefore displays very different properties for oxygen dissociation when compared to pure Pt nanoparticles. We have further shown that surface flexibility is not intrinsic property of nanoparticles. Core-shell interactions stabilise the Pt shell of Ti@Pt clusters reducing flexibility. Calculating $\Delta E^{\neq} / \mathrm{RMSD}$ gives an idea of the dependence of the dissociation barrier on surface flexibility. Values for this ratio are presented in Table 11 for the 38 and 79 atom clusters. The relationship between the RMSD at the TS and dissociation barrier $\Delta E^{\neq}$is plotted in Fig. $\mathrm{S} 3, \dagger$ while a plot of $\Delta E^{\neq} /$RMSD against $E_{\mathrm{b}}$ is presented in Fig. $\mathrm{S} 4 . \dagger$

Significantly lower $\Delta E^{\neq} / \mathrm{RMSD}$ values are obtained for the 3-fold hollow sites on the $\mathrm{Pt}_{38}(111)$ facet, where barrier free dissociation occurs. Higher values are found for all positions on $\mathrm{Pt}_{32} \mathrm{Ti}_{6}$ as well as position 5 on $\mathrm{Pt}_{38}$. This shows a strong relationship between the dissociation barrier and cluster distortion. For $\mathrm{Pt}_{79}$, significantly lower values are obtained for the 3-fold hollow sites 10 and 11, where barrier free dissociation occurs. $\Delta E^{\neq} / \mathrm{RMSD}$ for positions 8 and 9 on $\mathrm{Pt}_{79}$ are higher than those for 10 and 11 on $\mathrm{Pt}_{79}$, but lower than all positions on $\mathrm{Pt}_{60} \mathrm{Ti}_{19}$. In general, values for $\mathrm{Pt}_{79}$ are comparable with those for $\mathrm{Pt}_{38}$, one more indication that the $\mathrm{O}_{2}$ dissociation barrier and cluster distortion are strongly related.

The $\Delta E^{\neq} /$RMSD for the $\operatorname{Pt}(111)$ surface is $9.00 \mathrm{eV}^{-1}$. This is greater than for all positions on $\mathrm{Pt}_{38}$ or $\mathrm{Pt}_{32} \mathrm{Ti}_{6}$. The $\Delta E^{\neq} / \mathrm{RMSD}$ values for the $\mathrm{Pt}(111)$ slab are greater than those for $\mathrm{Pt}_{79}$. This once again demonstrates the very important differences between the Pt clusters and slab. For the $\mathrm{Pt}_{60} \mathrm{Ti}_{19}$ cluster, the majority of the $\Delta E^{\neq} / \mathrm{RMSD}$ values are greater than those for the

Table 11 Dissociation barrier $\Delta E^{\neq}$against RMSD $\left(\mathrm{eV} \AA^{-1}\right)$ for the 38 and 79 atom clusters at the TS. The value for the Pt(111) slab has also been calculated for comparisons ${ }^{a}$

\begin{tabular}{|c|c|c|c|}
\hline \multicolumn{2}{|c|}{38 Atom Cluster } & \multicolumn{2}{|c|}{79 Atom Cluster } \\
\hline Site & $\Delta E^{\neq} / \mathrm{RMSD}$ & Site & $\Delta E^{\neq} / \mathrm{RMSD}$ \\
\hline $\mathrm{Pt}_{38^{-5}}$ & 4.00 & $\mathrm{Pt}_{79}-8$ & 3.40 \\
\hline $\mathrm{Pt}_{32} \mathrm{Ti}_{6}-5$ & 6.20 & $\mathrm{Pt}_{60} \mathrm{Ti}_{19}-8$ & 13.20 \\
\hline $\mathrm{Pt}_{38}-6$ & 0.21 & $\mathrm{Pt}_{79^{-9}}$ & 2.63 \\
\hline $\mathrm{Pt}_{32} \mathrm{Ti}_{6}-6$ & 3.09 & $\mathrm{Pt}_{60} \mathrm{Ti}_{19^{-9}}$ & 20.00 \\
\hline $\mathrm{Pt}_{38-7}$ & 0.00 & $\mathrm{Pt}_{79-10}$ & 0.00 \\
\hline \multirow[t]{3}{*}{$\mathrm{Pt}_{32} \mathrm{Ti}_{6}-7$} & 8.86 & $\mathrm{Pt}_{60} \mathrm{Ti}_{19}-10$ & 11.50 \\
\hline & & $\mathrm{Pt}_{79^{-1}}$ & 0.33 \\
\hline & & $\mathrm{Pt}_{60} \mathrm{Ti}_{19-11}$ & 7.70 \\
\hline
\end{tabular}

${ }^{a} \Delta E^{\neq} / \mathrm{RMSD}$ for the $\mathrm{Pt}(111)$ surface is $9.00 \mathrm{eV} \AA^{-1}$. slab (excluding position 11), due to the reduced oxygen adsorption energy, coupled with the lack of flexibility of the Pt shell.

\section{Conclusions}

We found that when the adsorption strength of the $\mathrm{O}_{2}$ molecule on the cluster surface increases, the dissociation barrier will subsequently decrease. Hence, dissociation barriers on the alloyed Ti@Pt clusters would be found to be greater than those for the pure Pt clusters that exhibit larger $E_{\mathrm{b}}$ values. Further trends, outlined below, were discovered.

Pure Pt clusters are easily distorted when $\mathrm{O}_{2}$ is adsorbed on the (111) facet. Furthermore, sites which are relatively easily distorted facilitate barrier-free dissociation of $\mathrm{O}_{2}$, a trend which is not only seen for the small 38 atom clusters but also the larger 79 atom clusters. As for the alloyed Ti@Pt clusters, in all cases significant barriers are observed for all sites, which are greater than the barriers found for the pure Pt clusters.

The presence of the $\mathrm{O}_{2}$ dissociation barriers for the Ti@Pt clusters is attributed to rigidity enhancement of the Pt shell by the Ti core. Significant electron donation is observed from Ti to Pt suggesting strong interactions between the two, which coincides with significantly less distortion of the Ti@Pt clusters, upon binding $\mathrm{O}_{2}$, when compared to the pure Pt clusters.

The presence of the barrierless dissociation on the (111) facet of the pure Pt cluster suggest that small Pt clusters would efficiently activate $\mathrm{O}_{2}$. However, the relatively strong adsorption strength of oxygen to the Pt surface, compared to the alloyed Ti@Pt cluster found in previous studies, means that it would be difficult to remove the resulting oxygen species from the pure Pt cluster surface. Therefore, whilst $\mathrm{O}_{2}$ dissociation would require greater energetic input on the surface of the Ti@Pt clusters, the resulting species (following further transformations to e.g. $\mathrm{H}_{2} \mathrm{O}$ or $\mathrm{H}_{2} \mathrm{O}_{2}$ ) would be easier to remove from the surface due to the weaker Pt-O interactions compared to the pure Pt cluster.

A very attractive development in the direction of optimal catalyst properties, resulting from findings of the present study, would be substitution of $\mathrm{Ti}$ in the core of Pt-based bimetallic particles by another metal (M). The ideal $\mathrm{M}$ core would weaken adsorption of atomic oxygen compared to pure Pt, to allow for fast ORR kinetics in the later stages of the reaction (as Ti does), but form weaker Pt-M bonds than Pt-Ti, thus maintaining the kinetic flexibility of the Pt shell which is advantageous for $\mathrm{O}_{2}$ dissociation.

\section{Acknowledgements}

This research was funded through the RCUK doctoral training centre in hydrogen, Fuel cells and their applications (EP/ G037116/1). Financial support was also provided by the EU (FP7-NMP.2012.1.1-1 project ChipCAT, Ref. No 310191) and the Spanish MICINN (CTQ2012-34969, FIS2008-02238). The authors thank COST Action MP0903: "Nanoalloys as Advanced Materials: From Structure to Properties and Applications", as well as COST Action CM1104. Much of the work has been performed under the HPC-EUROPA2 project (project number: 228398) with 
the support of the European Commission - Capacities Area Research Infrastructures. The computations described in this paper were performed in part using The University of Birmingham's BlueBEAR HPC service, which was purchased through HEFCE SRIF-3 funds, and via our membership of the UK's HPC Materials Chemistry Consortium, which is funded by EPSRC (EP/F067496). This work made use of the facilities of HECTOR, the UK's national high-performance computing service, which is provided by UoE HPCx Ltd at the University of Edinburgh, Cray Inc and NAG Ltd, and funded by the Office of Science and Technology through EPSRC's High End Computing Programme. Computational time granted by the Barcelona Supercomputing Centre on the Marenostrum supercomputers is also gratefully acknowledged. H. A. A. thanks the Ministerio de Educación for a post-doctoral grant (SB2010-0172), Bulgarian Science Fund (grant DCVP 02/1) and FP7 project BeyondEverest for support.

\section{References}

1 Q. Fu, J. Yang and Y. Luo, J. Phys. Chem. C, 2011, 115, 68646869.

2 M. Stamatakis and D. G. Vlachos, ACS Catal., 2012, 2, 26482663.

3 D. J. Schmidt, W. Chen, C. Wolverton and W. F. Schneider, J. Chem. Theory Comput., 2012, 8, 264-273.

4 J. M. Bray and W. F. Schneider, Langmuir, 2011, 27, 81778186.

5 A. Smeltz, R. Getman, W. Schneider and F. Ribeiro, Catal. Today, 2008, 136, 84-92.

6 R. Getman, W. Schneider, A. Smeltz, W. Delgass and F. Ribeiro, Phys. Rev. Lett., 2009, 102, 076101.

7 W. Chen, D. Schmidt, W. F. Schneider and C. Wolverton, J. Phys. Chem. C, 2011, 115, 17915-17924.

8 R. B. Getman, Y. Xu and W. F. Schneider, J. Phys. Chem. C, 2008, 112, 9559-9572.

9 D.-H. Lim and J. Wilcox, J. Phys. Chem. C, 2011, 115, 2274222747.

10 M. Kettner, W. B. Schneider and A. A. Auer, J. Phys. Chem. C, 2012, 116, 15432-15438.

11 Y. Xu, W. A. Shelton and W. F. Schneider, J. Phys. Chem. A, 2006, 110, 5839-5846.

12 D. Cheng and W. Wang, Nanoscale, 2012, 4, 2408-2415.

13 A. Chandan, M. Hattenberger, A. El-kharouf, S. Du, A. Dhir, V. Self, B. G. Pollet, A. Ingram and W. Bujalski, J. Power Sources, 2013, 231, 264-278.

14 A. Pollet, J. E. Newton, J. A. Preece and O. J. Curnick, ECS Trans., 2011, 2165-2173.

15 O. J. Curnick, P. Mendes and B. Pollet, ECS Trans., 2010, 557561.

16 O. J. Curnick, P. M. Mendes and B. G. Pollet, Electrochem. Commun., 2010, 12, 1017-1020.

17 B. Li and S. H. Chan, Int. J. Hydrogen Energy, 2013, 38, 33383345.

18 P. Mani, R. Srivastava and P. Strasser, J. Power Sources, 2011, 196, 666-673.
19 R. Othman, A. L. Dicks and Z. Zhu, Int. J. Hydrogen Energy, 2012, 37, 357-372.

20 J.-Y. Choi, R. S. Hsu and Z. Chen, J. Phys. Chem. C, 2010, 114, 8048-8053.

21 L. Calvillo, M. Gangeri, S. Perathoner, G. Centi, R. Moliner and M. Lázaro, Int. J. Hydrogen Energy, 2011, 36, 98059814.

22 B. Seger and P. V. Kamat, J. Phys. Chem. C, 2009, 113, 79907995.

23 P. C. Jennings, B. G. Pollet and R. L. Johnston, Phys. Chem. Chem. Phys., 2012, 14, 3134-3139.

24 P. C. Jennings, B. G. Pollet and R. L. Johnston, J. Phys. Chem. C, 2012, 116, 15241-15250.

25 G. Kresse and J. Hafner, Phys. Rev. B: Condens. Matter Mater. Phys., 1993, 47, 558-561.

26 G. Kresse, Phys. Rev. B: Condens. Matter Mater. Phys., 1996, 54, 11169-11186.

27 G. Kresse and J. Furthmüller, Comput. Mater. Sci., 1996, 6, 15-50.

28 G. Kresse and J. Hafner, Phys. Rev. B: Condens. Matter Mater. Phys., 1994, 49, 14251-14269.

29 P. E. Blöchl, Phys. Rev. B: Condens. Matter Mater. Phys., 1994, 50, 17953-17979.

30 G. Kresse, Phys. Rev. B: Condens. Matter Mater. Phys., 1999, 59, 1758-1775.

31 J. P. Perdew, K. A. Jackson, M. R. Pederson, D. J. Singh and C. Fiolhais, Phys. Rev. B: Condens. Matter Mater. Phys, 1992, 46, 6671-6687.

32 J. Perdew, J. Chevary, S. Vosko, K. Jackson, M. Pederson, D. Singh and C. Fiolhais, Phys. Rev. B: Condens. Matter Mater. Phys., 1993, 48, 4978.

33 D. Sheppard, P. Xiao, W. Chemelewski, D. D. Johnson and G. Henkelman, J. Chem. Phys., 2012, 136, 074103.

34 J. Kästner and P. Sherwood, J. Chem. Phys., 2008, 128, 014106.

35 R. F. W. Bader, Atoms in Molecules: a Quantum Theory, Oxford University Press, New York, 1994.

36 W. Tang, E. Sanville and G. Henkelman, J. Phys.: Condens. Matter, 2009, 21, 084204.

37 S. M. Kozlov and K. M. Neyman, Top. Catal., 2013, 56, 867873.

38 H. Steininger, S. Lehwald and H. Ibach, Surf. Sci., 1982, 123, 1-17.

39 C. Puglia, A. Nilsson, B. Hernnäs, O. Karis, P. Bennich and N. Mårtensson, Surf. Sci., 1995, 342, 119-133.

40 A. Eichler and J. Hafner, Phys. Rev. Lett., 1997, 79, 44814484.

41 K. Gustafsson and S. Andersson, J. Chem. Phys., 2004, 120, 7750-7754.

42 Z. Duan and G. Wang, Phys. Chem. Chem. Phys., 2011, 13, 20178.

43 D. J. Miller, H. Öberg, L.-A. Näslund, T. Anniyev, H. Ogasawara, L. G. M. Pettersson and A. Nilsson, J. Chem. Phys., 2010, 133, 224701.

44 L. Qi, J. Yu and J. Li, J. Chem. Phys., 2006, 125, 054701.

45 V. Šljivančanin and B. Hammer, Surf. Sci., 2002, 515, 235244. 
46 B. Stipe, M. Rezaei, W. Ho, S. Gao, M. Persson and B. Lundqvist, Phys. Rev. Lett., 1997, 78, 4410-4413.

47 J. R. Kitchin, J. K. Nørskov, M. A. Barteau and J. G. Chen, J. Chem. Phys., 2004, 120, 10240-10246.

48 P. Gambardella, V. Šljivančanin, B. Hammer, M. Blanc, K. Kuhnke and K. Kern, Phys. Rev. Lett., 2001, 87, 056103.
49 P. Feibelman, S. Esch and T. Michely, Phys. Rev. Lett., 1996, 77, 2257-2260.

50 M. Shao, A. Peles and K. Shoemaker, Nano Lett., 2011, 11, 3714-3719.

51 Z. Duan and G. Wang, J. Phys. Chem. C, 2013, 117, 62846292. 